\title{
Analysis on the "Heritage Loss" Phenomenon of the National Traditional Sports from the "Heritage Application" of Korea for the Tug-of-War
}

\author{
$\mathrm{Li} \mathrm{Li}$ \\ Shaanxi Xueqian Normal University \\ Xian, China
}

\begin{abstract}
On December 2, 2015, Korea together with Vietnam, Cambodia and Philippine successfully applied to UNESCO for making the tug-of-war as the human intangible cultural heritage, which soon attracted the concern and discussion of China's media and other social people from all walks of life .Tug-of-war originated from China and had a long history in China, so it should be China to get the successful results. The success of Korea, however, has shown the significant problems of China in protection, promotion and inheritance of Chinese traditional sports culture. A basic introduction to the traditional sports and world culture heritage application will be shown in this article to reveal the success of heritage of Korea by the universally applicable rules the reasons, and research the "lost" of traditional sports in our country by comparing, and then find suitable protection strategy for the development of traditional sports in China.
\end{abstract}

Keywords—world culture heritage application; national traditional sports project; heritage loss

\section{BASIC CONTENT FOR HERITAGE APPLICATION}

\section{A. Concept of Heritage Application and Its Condition for} Intangible Cultural Heritage

1) Concept of heritage application: Heritage application is a kind of activity that some countries and areas of the world apply for their special heritage value to the UNESCO heritage committee for adding in the world heritage. According to the regulations of UNESCO, "Intangible cultural heritage"includes oral traditions and expression form, the performing arts, social practices, rituals and festivals, knowledge about nature and the universe, practice and traditional crafts. According to the latest rules of the world heritage committee, in principle, a country now only has two application places for material heritage projects every time, and there is at least one natural heritage project. Meanwhile, the same project can be applied by one country or by several countries, if it is done by several countries, it will only cost the place of one of them. Just like Korea, who applied for tugof-war, took good use of this rule by united the other 3 countries for heritage application[1].

2) Heritage application condition for intangible cultural heritage: a) It should be the concentrated reflection of intangible cultural heritage with special value

b) It should be traditional folk culture with special value at the aspects of history, art, ethnology, sociology, anthropology, linguistics and literature.

c) In order to be declared as the human oral outstanding works or excellent intangible cultural heritage, the cultural space or cultural expression for application should conform to the five conditions regulated in "the human oral outstanding works and excellent intangible cultural heritage declared by UNESCO'. So, the applied works should:

d) It deeply rooted in the cultural tradition or the related community cultural history.

e) It can be as a means to affirm the role of the folk cultural features and the related cultural community, has an important value has important value in intelligence and communication, and promote the relations among all ethnic groups and various social groups, plays a reality role in cultural and social aspects to the related groups.

f) It can develop the technology well and improve the technical quality.

g) It has the unique certificating value to the modern tradition.

h) It faces the disappearing dangers due to the lack of rescue and protection, or the acceleration of evolution process, or the process of urbanization trend, or adapt to the new environment influence.

3) Application way: Each member only can apply one national work in every two years. The multi-ethnic works of the multinational community can be applied outside the limits of each country. The applying works can be applied via the following ways:

a) applied by the member or the governments of the united countries;

b) applied after listening all suggestions from the NESCO committees of the related countries by organizing the meeting among governments; 
c) applied after the non-governmental organizations, which has formal relations with UNESCO, listened to the suggestions of UNESCO committees of his own country. The applied works should be attached with the name of the owner or the words, audio, video accepted by people or the other certifications, or it can not be applied.

\section{B. Meaning for Heritage Application}

The project of heritage application will get much more focus from the society, and can increase the confidence and proud of the people; after the success of heritage application, it will get special protection fund to promote the protection and development of this project; it is difficult to deeply understand culture of other countries for many foreigners, but the projects at the name list of the intangible cultural heritage can get better acquaintance and focus from the international social group; at the same time, the heritage application can promote the inheritance and development for the excellent folk culture.

\section{THE BASIC CONTENT OF NATIONAL TRADITIONAL SPORTS}

\section{A. Concept of National Traditional Sports}

National traditional sports is a kind of sports style that created by world people from different nations to meet the requirements both from body and spirit of people at different historical times.

As the name suggests, the national traditional sports includes three meanings, one is sport, two is nation, three is tradition.

- So-called sports, it refers to such activities or sports projects have the characteristics of sports, with the purposes and plans, people exercise their body according to a certain regulations to make their body get balanced development.

- So-called nations, it refers to such activities or sports has national features, which is mainly displayed on national culture background. The national culture background is mainly shown via: its activities or sports are chosen from special nations, which display the cultural traditions and customs of this nation, and are liked by public and have deep national and public basics in this national field.

- So-called tradition, it refers to this sports can be succeeded generation by generation. This kind of sports are created in a particular cultural background and a certain historical stage, eliminate its dregs and keep its essence in the process of historical development and become mature gradually, which has the national ethnic style and is an important part of national traditional culture.

\section{B. National Traditional Sports Classes and Development States of Our Country}

Chinese traditional sports is the general name for the sports activities which circulated or inherited in one or many nations in Chinese history, which mainly refers to our traditional projects like illnesses, fitness, martial arts and entertainments. Traditional ethnic sports of our country is divided into three categories: sprots (Sanda) attack and strong force, entertaining folk activities projects, keeping in good health fitness sport.

The first class projects mainly include boxing, apparatus and instruments, track and field, leisure and entertainment.

The second class projects include playing, dancing, playing ball, boating, playing water, playing ice and snow, playing chess, snatching the firework; tug-of-war, swing, kites, playing gyro, kicking, playing shuttlecock, rope skipping, Tau Hu, and other items.

The third class projects include Taiji and vigorous dance.[2]

Chinese Kongfu is profound, as the most widespread Kongfu, Tai Chi, our country has applied it as human intangible cultural heritage for five times but all failed[3].In 2008, our country applied Taijiquan as heritage for the 1st time, and there was a great chance of success in that year. Surprisingly, the UNESCO is unhappy because China applied too many projects, so the Taijiquan had not entered the stage of the review, and regrets to say goodbye. In 2009, China did the 2nd application for it. Jiaozuo City again applied Taijiquan as the intangible heritage and successfully sent the application documents to the headquarter of UNESCO. However, UNESCO limited the number again in 2009 and finally China decided to apply for Peking Opera and Chinese medicine acapuncture and moxibustion, Taijiquan was held again. After these two times for intangible heritage application, NESCO returned the application for every 2 years, each country only can apply one project. In 2011, our country applied for shadow play, not for Taijiquan. In 2013, our country applied for abacus, there was no Taijiquan again. In 2014, the application text of Taijiquan, video failed to submit before the deadline, then the fifth time failed. From this view, the five times for application heritage for Taijiquan, the later 3 times even didn't come across the threshold of our country but failed before its competitors in China.

\section{BASIC ANALYSIS OF “HERITAGE APPLICATION”FOR THE} TUG-OF-WAR OF KOREA

\section{A. General States of "Heritage Application"for the Tug-of- War of Korea}

According to the news form the Korean cultural property hall on Dec.2, the 10th intergovernmental meeting protecting the intangible cultural heritage held in Windhoek, capital of Namibian by UNESCO passed a resolution that formally recorded the "tug-of-war" applied by the 4 countries, Korea, Vietnam, Cambodia and Philippine into the human nonmaterial cultural heritage list. From then on, the tug-of-war had become as the 18th human non-material cultural heritage of Korea.

According to the report, as a framing game with harvest wish, the tug-of-war is very popular in rice cultural circle including Korea. In March last year, Korea, Vietnam, Cambodia and Philippine united together for application of the tug-of-war. In Nov. of this year, the perform subsidiary of the intangible heritage committee of UNESCO give their 
"supplementary information" to the heritage application of the tug-of-war, who think that as a human non-material cultural heritage, the tug-of-war has good value, but it need to perfect the relevant specification. Therefore, the related people of the mentioned 4 countries tried their best to persuade the members of the local committee, and finally make the tug-of-war properties success.

\section{B. Reason Analysis for the Success of "Heritage Application" of Tug-of-War for South Korea}

1) Strong protection consciousness, good promotion: When the economy is rising in Korea, the culture is also rising at the same time, which has close relation with the protection consciousness of Korea people and the government to the traditional culture. In Korea, the traditional festival is a national holiday, and it is a day that everyone can feel the traditional humanities atmosphere.

In recent years, Korea, on the promotion of tug-of-war and culture about it, has done her utmost. The tug-of-war competition held in Junjishi Village, Tangjin County, locating in the south of Seoul, $120 \mathrm{~km}$ from it, is very famous in Korea. It even held annual international competition in this place. The competition of tug-of-war in Jichishi village has 450years history, and has been taken as the oldest tug-of-war competition in Korea. According to the Korea customs, the tug-of-war among children will be held between two villages on Jan.12 and 13t then a large scale of the tug-of-war among the adult male will be held in the next day. Except for the prize, the winner also can carry all the rope of the loser and go back to village for celebration. In the show Running Man of Korea, the team tug-of-war is often displayed. In addition, the tug-ofwar alliance between Korea and Japan has begun their propaganda in 2014 to try to return the tug-of-war to the Olympic family. Pointed out in the application that the tug-ofwar can let more folk amateur player board the stage of the Olympic Games, and the rules is relatively simple, it is team activity that many player can take part in, and to decide the winner will cost too much time and it is good for television relay and so on, so the tug-of-war worth to return to the Olympic family.

2) Pay much attention to the national tradition culture education: In the aspect of national traditional culture education, Korea has pulled much investment. According to statistics, most parents received education of South Korea will explain patiently the cultural relics and its culture when they take their children to visit the museum, which full shows the consciously concerns to the national history of the ordinary Koreans and the active consciousness of culture enlightenment for the next generation. In contrast, the consciousness of culture and education of many Chinese parents to the children is weak. Like Tu Youyou, who just won the Nobel Prize for medicine, said in a speech: Artemisinin is a gift to the world given by the traditional Chinese medicine, Chinese medicine is a great treasure. Artemisinin is excavated from the treasure house. She called for all mankind to find rich treasure of traditional Chinese medicine, to appreciate the charm of Chinese culture.
The emphasis to the traditional culture in Korea has been shown as evidence, which is worthy of the Chinese government and people to ponder.

\section{IV. “LOSS OF HERITAGE”OF OUR NATIONAL TRADITIONAL SPORTS AND ITS MEASURES}

\section{A. Basic Analysis to the "Loss of Heritage"}

1) Late protection, project succession is not implemented: Xiaorong Chen, director of the China sports non-material cultural heritage research center of Shenzhen university, has said in an interview with the China youth daily in early time that China's traditional sports are variety and the quantity is huge, but because the protection to the "intangible" of Chinese traditional sports started late, and previous departments in charge of sports took the competitive sports as the core, "until now, how to protect the Chinese traditional sports, there are a lot of fields is still blank."Now not only a few of the Chinese traditional sports is decline or even disappear, even some traditional sports with mass base also meet the periphery "registered". There are lag and loopholes in the protection of traditional culture in our country. As early as in 1962, Korea has enacted the Protection Act for Koeran Cultural Property, which not only provides legal protection for the national culture and also promotes the protection concepts to the folk culture. In 1998, Korea formally took "culture industry" as its economic pillar industry in the 21 st century. According to some folk experts, " Korea applies for heritage is to push its own culture outside of its country, the process is more important than the result.

2) The process of heritage application is too complex, and many projects are not started: In 2011, Siming Liu, the president of China's $\mathrm{Ki}$ in at that time, said, application for world class for I-go and Chinese chess is not started till now, "because this work needs too much and complex document and process, the work quantity is very large, thus it is not easy to start it and there is no plan for it temporarily."

3) There are too many traditional sports in Chine, but the places are limited: As one of the four ancient civilizations, China's long history created much brilliant human culture, and made an indelible contribution to world civilization. China is humongous, long history background produced many of the traditional sports, including the Chinese Kongfu and Taijiquan etc. that haven't successfully been applied as the heritage. In many projects, the government must comprehensively consider the value of properties for each project and promote the popularity and public benefit. Due to the quota restrictions, a lot of traditional sports are arranged behind, which provides the "chance" to the country that has the similar projects, thus, many of the heritage applications are blocked.

\section{B. Measures Analysis for Solving "Loss of Heritage"}

The president Jinping $\mathrm{Xi}$, in the host of the 12th group learning of the political bureau of the central committee in 2013, pointed out that to improve the national cultural soft 
power is important for realizing the "two one-hundred" goals and the realization of the great rejuvenation of the Chinese nation. In today's construction of socialist culture power, we should fully realize the importance of the Chinese traditional culture. It is important to emphasis on quality for applying the heritage, not on quantity. The purpose for heritage application is to spread the excellent Chinese traditional culture in the world, not to pursuit the quantity. The following items should be carried out in order to well develop and popular our traditional sports and make them get focus from the world.

1) Focus on the process of protection and inheritance: At present, there are a lot of people still misunderstand the heritage application, and take it as a patent application, and then think that the one originated from China should be applied by China, and only pay attention to the one successful applied. It is necessary to balance the public's point of view via announcement and education. It is not right to take successful heritage application as a title or as a patent, or pay too much attention to the result of heritage application. Heritage application is a kind of method for the international community to understand the means of a national culture, but the most fundamental content is to carry out our culture well in home, anyway, it is our root. We cannot simply think that other countries apply for "Korean medicine science" is to plunder China's cultural heritage, the key point for the people is how to establish effective mechanism and protection of traditional culture. Koreans told us that a nation must have their own style to survive confidently, and deep respect their own history, respect their ancestors. A nation lost their own culture can not stand out among the nations of the world, one cannot feel, mining, carries forward the excellent culture of our nation, never is standing state. One nation can't stand firmly if he can not feel, dig and spread his own outstanding culture.

2) The multinational cooperation among many countries: Due to the limited places in each country in application, meanwhile, with the purpose of protecting and developing culture, it is possible to unite several countries with the similar traditional sports to applied together, which not only can share the preparation for documents and other procedures, and also reduce the pressure of national application, save the application places and is good for protecting and inheriting the similar excellent culture.

3) To keep pace with The Times, and carry on innovation: When we protect the traditional sports culture, it is necessary to timely innovate the traditional sports culture and make this culture can better penetrate into people's left, so that it can much more support. To lack of new style is one of the reason that the traditional festivals are not popular with young people. I t is well known, for example, that we have Zongzi at the Dragon Boat Festival, Green rice ball at the Qingming Festival, Dumplings for the Lantern Festival and Moon cakes for the Mid-autumn festival and so on. At present, the Chinese satisfied with their requirements for food and clothing can eat at any time with any amount, so the traditional festivals seem to lose their charm soon. In the protection of the traditional festival, we should have the notion of advancing with the Times. If we don't pay attention to our own culture, it will not form the unique memory style, not endowed with new connotation in the new period, and some good, ethnic, traditional things will slowly disappear, and die. We should pack our rich cultural resources as a kind of commodity that recognized by the world.

4) Pay attention to the education of traditional sports, establish a scientific and perfect protection mechanism: Education is an important part to cultivate and develop the national quality, it is necessary to scientifically blend the national tradition sports knowledge and skills in the students' teaching practice to make it as the basic fitness requirements, so that to cultivate the people's application consciousness on traditional sports.

Of course, when we create and develop the cultural industry, the most taboo is to desperately rescue cultural heritage, while in other side, the folk cultural heritage is damaged by us. Cultural serve the social harmony, we not only should make the culture become as the motivation of the social harmony, but also achieve internal harmony for culture. To the protection for the traditional culture, we did have lag and loopholes. The establishment of a scientific protection mechanism not only provides legal protection for the national culture protection, also promote the folk culture protection concepts [6].

Independent intellectual property rights are not only shown on high technology. We have a lot of excellent traditional culture which covers all aspects of intellectual property rights, so it isn't necessary to be worried when others want to take it away. Of course, "heritage application" is the affirmation of the traditional culture. "Heritage application" should not become as a kind of occasion. If China doesn't actively take part in the competition field of the international culture industry, we will be possible to lose the international speech right in cultural and industry field. Some people say that Chinese diet culture can be regarded as the fifth largest Chinese civilization created by the Chinese. The Chinese, early moved to abroad, all make a living by opening a Chinese restaurant. However, if we don't register for Chinese cuisine, it may become of Japan. One of the heavy lessons on the protection of the cultural properties is our famous arts and crafts, Jingtailan, while at present, Japan's exports has accounted for more than $80 \%$ in the international market. The Chinese traditional medicine is not only a kind of medicine, but also is a kind of culture, and if we don't pay much attention to it, it may be applied by Korea again.

\section{REFERENCES}

[1] Convention on Protecting the World Culture and Natural Heritage, UNECSO, 1972.11.

[2] Suzhe Zhao, Clarification and Development for the National Traditional Sports, Sport Journal, 2007,14(5):78-81.

[3] Yindong Li, Kongfu Explanation-- Explanation to the Kongfu Feature and Its Functional Value System, Beijing sport university press, 2006. 
[4] Successful Heritage application for "Silk Road", New silk road: the path to the common prosperity, People's Daily Online, 2014.06.

[5] Xiaoli Wang. Guide and regulate the culture property protection and develop national culture[J]. Academic trends: Beijing, 2006(6):14-17.

[6] Yalin Wang, Dengxun Jia. Discussion on the ecological development of the national culture industry and its institutional guarantee[J]. Journal of Lanzhou University: Social and science edit, 2014(3):141-148. 